\title{
PLANTAS ALIMENTÍCIAS NÃO CONVENCIONAIS: UTILIZAÇÃO DAS FOLHAS DE "ORA-PRO-NOBIS" (PERESKIA ACULEATA MILL, CACTACEAE) NO CONSUMO HUMANO.
}

\author{
NON-CONVENTIONAL EDIBLE PLANTS: THE USE OF "ORA-PRO-NOBIS" \\ (PERESKIA ACULEATA MILL., CACTACEAE) LEAVES IN HUMAN CONSUMPTION.
}

\author{
Aline Fernanda Cruz', Aline Savicki', Alis Eugenio Frentzel', Isadora Padilha Adam', \\ Larissa de Oliveira Prado', Lorena Franqueto', Maria Eugenia Balbi² ${ }^{\star}$
}

1 - Discentes do curso de Farmácia, Universidade Federal do paraná (UFPR)

2 - Docente do curso de Farmácia, Universidade Federal do Paraná (UFPR)

\section{RESUMO:}

A ora-pro-nóbis (Pereskia aculeata) é uma cactácea popularmente conhecida como "carne de pobre" devido ao seu uso popular pelo teor de proteína encontrado em suas folhas e seu baixo custo, sendo classificada como uma Planta Alimentícia Não Convencional (PANC). Possui ampla distribuição, sendo encontrada principalmente na América Central, Índia Oriental, América do Norte e no Brasil, reforçando a sua característica de ser facilmente cultivada sem depender de um solo fértil, conferindo à Pereskia aculeata um notável potencial para sua aplicação na prevenção e no tratamento de condições relacionadas a deficiências nutricionais. Tendo em vista todos os benefícios da planta, o objetivo geral do trabalho consistiu em analisar a composição química e nutricional da "ora-pro-nóbis" a fim de difundir sua utilização à população vegetariana e vegana, sendo os objetivos específicos o desenvolvimento de uma farinha e aplicação de um questionário para avaliar o perfil de consumo da cactácea. Para isso, as folhas de ora-pro-nóbis foram coletadas na cidade de Campo Largo e, em sequência, higienizadas e passadas por um processo de quarteamento para subsequente amostragem. Foram feitas análises morfológicas superficiais, determinações de umidade, de proteínas, de lipídios, de fibras, de minerais e de carboidratos, seguindo as metodologias do Instituto Adolfo Lutz (IAL) e a Association of Official Agricultural Chemists (AOAC), e aplicação de um questionário por meio da plataforma Google Formulários. A partir disso, os resultados para proteínas encontrados foram relativamente mais baixos quando comparados à literatura, sendo isso justificado pela sazonalidade. Por fim, pode-se concluir a partir dos resultados que a Pereskia aculeata supre o papel como fonte alternativa de proteínas se consumida na forma de farinha. Além disso, obteve-se no questionário que o consumo mais prevalente da ora-pro-nóbis era in natura ou na forma de saladas, reforçando a importância da divulgação do presente trabalho acadêmico à comunidade externa, visto que consumindo a cactácea na sua forma fresca, não se obtém uma quantidade significante de proteínas.

PALAVRAS-CHAVE: ora-pro-nobis; Pereskia aculeata; carne de pobre; proteína; suplementação proteica; vegano; vegetariano.

\section{ABSTRACT:}

Ora-pro-nobis (Pereskia aculeata) is a species of cactus popularly known as "poor man's meat" due to its popular use and protein content of its leaves and its affordable price, being classified as a Non-Conventional Edible Plant (NCEP). Furthermore, it is widely available, 
being found in North and Central America, Brazil and in Oriental India, reinforcing the fact that it can be easily cultivated without the need of fertile soil, what grants to Pereskia aculeata a notable potencial to its application in prevention and treatment of conditions related to nutritional deficiencies. With a full picture of all the benefits the plant provides, the general objective of this paper consists in analyzing the chemical and nutritional composition of the "Ora-pro-nobis" to promote its use in the vegan and vegetarian communities, with the specific objective of creating a plant-based powder and the application of a survey to evaluate the profile of consumption of this cactus. To achieve this, leaves of Ora-pro-nobis were collected in the city of Campo Largo and proceeded to be sanitized and divided for the subsequent sampling. There were conducted superficial morphological analysis, determination of humidity, protein, carbohydrate, lipids, fibers and minerals, all according to the methodology of the Adolfo Lutz Institute (ALI) and the Association of Official Agricultural Chemists (AOAC) and the application of a survey through Google Forms. From there, the results showed that the levels of protein were lower than the references, which can be explained by seasonality. It can be concluded, through the results, that the Pereskia aculeata can be used as an alternative source of protein if ingested in its powdered form. And the survey showed that the prevalent method of consumption was in its natural form or in salads, reinforcing the need to disclose this study to the public to raise awareness to the fact that that method of consumption did not provide a significant amount of proteins.

KEY WORDS: ora-pro-nobis; Pereskia aculeata; poor man's meat; protein; protein supplementation; vegan; vegetarian.

\section{INTRODUÇÃO}

\subsection{Classificação Botânica}

A Pereskia aculeata, que possui como sinônimos "ora-pro-nóbis" e "carne de pobre" (QUEIROZ, 2012), é conhecida como uma planta de quintal com alto teor proteico e é largamente utilizada por populações urbanas ou rurais, já que é capaz de enriquecer a alimentação sem possuir um alto custo (SOUZA et al., 2009). A ora-pro-nóbis é considerada uma planta de consumo alimentar não convencional de acordo com o guia de Plantas Alimentícias Não Convencionais (PANC) do Brasil (BRASIL, 2010).

Essa cactácea é largamente encontrada nas regiões da América Central, contudo pode estar em alguns lugares da Índia Oriental, na América do Norte principalmente na Flórida (AGOSTINI-COSTA et al., 2012; ALMEIDA FILHO; CAMBRAIA, 1974; TAKETI et

al., 2009) e até mesmo no Brasil nos estados do Maranhão, Pernambuco, Bahia, Alagoas, Sergipe, Paraná, Santa Catarina, Rio Grande do Sul, Minas Gerais, Espírito Santo, São Paulo e Rio de Janeiro. O fato da "ora-pro-nóbis" ser amplamente distribuída em vários continentes reforça a sua característica de ser facilmente cultivada sem depender de um solo muito fértil, adaptando-se praticamente em todos os tipos de solo, apesar de preferir climas tropicais e subtropicais e depender de luz solar plena (SILVEIRA, 2010; SOUZA et al., 2010). 
Seu cultivo ocorre por meio de um fácil desenvolvimento e crescimento rápido, dado que possui enraizamento objetivo e propagação por meio de estaquia caulinar, isso é, a partir de partes do caule, raiz ou folha é possível desenvolver novas plantas. Essas características ainda são favorecidas, visto que a Pereskia aculeata sofre pouca incidência de doenças e pragas (SILVA JÚNIOR et al., 2010).

A Pereskia aculeata pertence ao reino Plantae, classe Magnoliopsida, ordem Caryophyllales e família Cactaceae (KINUPP; BARROS, 2008) e segundo o Tropicos (2019) e o The Plant List (2019), a descrição dessa espécie teve como autor Phlip Mill, apesar do gênero Pereskia ter sido descrito em 1703 por Plumier em uma homenagem à Nicolas Claude Fabri de Peiresc, de acordo com Scheinvar (1995).

No caso da Pereskia aculeata Mill, a espécie analisada neste artigo, suas características são de uma trepadeira, capaz de crescer mesmo sem apoio (SILVEIRA, 2010; SOUZA et al., 2010), com bom desenvolvimento o ano inteiro (ALMEIDA FILHO; CAMBRAIA, 1974). Além disso, tem as características de Angiosperma do tipo eudicotiledônea, com semente, caules, folhas e fruto (DUARTE; HAYASHI, 2005; LOPES et al., 2008; ROSA; SOUZA, 2003).

\subsection{Valores Nutricionais e Medicinais}

As folhas de Pereskia aculeata Mill. são utilizadas na culinária tradicional de algumas regiões do país. Além do uso culinário, as folhas são detentoras de compostos químicos ativos de ação farmacológica, possuindo propriedades medicinais cicatrizantes e anti-inflamatórias (DUARTE; HAYASHI, 2005; ROSA; SOUZA, 2003).

Em primeira análise, cabe salientar que essa cactácea, por conter proteínas essenciais e de boa qualidade, possui notável capacidade na prevenção e no tratamento de condições relacionadas a deficiências nutricionais, principalmente as proteicas (SILVEIRA, 2010). Além disso, seu conteúdo proteico tem cerca de $85 \%$ de digestibilidade e contém elevados teores de aminoácidos essenciais, tendo como destaque a lisina, leucina e valina (MAZIA, 2012).

Ademais, a ora-pro-nóbis também possui bons níveis de fibras alimentares e minerais, tendo como destaque o cálcio e o ferro (ALMEIDA et al., 2014; ROCHA et al., 2008), além de apresentar teores de carboidrato e de minerais como fósforo, magnésio e cobre (TOFFANELI; RESENDE, 2011). Por fim, devido ao fato da Pereskia aculeata possuir um valor nutricional relevante, a Pastoral da Criança recomenda a utilização da sua farinha 
para complementar a alimentação e auxiliar no tratamento da desnutrição infantil em comunidades carentes (BATISTA et al., 2004). Dessa forma, pode-se perceber o grande potencial de nutrição alternativa, complementar e econômica que a ora-pro-nóbis tem para oferecer.

\subsection{Composição Nutricional}

A composição nutricional da ora-pro-nóbis tem sido descrita regularmente na literatura, sendo portanto o objetivo do trabalho apenas reforçar o caráter nutritivo relevante que essa planta apresenta. A porcentagem de proteínas na massa seca tende a estar entre 17,45\% (ALMEIDA FILHO; CAMBRAIA, 1974) e 28,4\% (TAKETI et al., 2009) enquanto que a umidade se encontra em um intervalo menor, de 86,81\% a 89,50\% (TAKETI et al., 2009). Quanto aos valores de fibras, carboidratos, lipídeos e minerais, encontram-se valores de 39,27\%, 24,8\%, 2,07\% (MARTINEVSKI, 2013) à 4,9\% (TAKETI et al., 2009) e de 13,66\% (MARTINEVSKI, 2013) à 22\% (ALMEIDA FILHO; CAMBRAIA, 1974), respectivamente.

A composição de micronutrientes também costuma ser explorada, encontrando-se, principalmente, altos níveis de minerais como fósforo (150 mg), manganês (46,4 mg) e zinco (26,7 mg) em $100 \mathrm{~g}$ de folhas frescas (TAKETI et al., 2009). Quanto ao conteúdo de aminoácidos, triptofano, leucina e arginina são os aminoácidos essenciais em maior quantidade, com 5,52 g, 2,00 g e 1,44 g por $100 \mathrm{~g}$ de massa seca (TAKETI et al., 2009), respectivamente. Já os aminoácidos não essenciais mais encontrados são o ácido glutâmico (26,7 mg de massa seca), ácido aspártico (17,1 mg de massa seca) e alanina (13,6 mg de massa seca) (TAKETI et al., 2009).

\subsection{Produtos no Mercado}

A ora-pro-nóbis pode ser encontrada no mercado na forma de pós, cápsulas, folhas desidratadas para chás e até mesmo formas mais incomuns, como antepasto. Os pós podem ser diluídos em água ou sucos, ou ainda serem utilizados na preparação de bolos, pães, massas, biscoitos e temperos.

\subsection{Objetivos}

O objetivo geral do trabalho consistiu em verificar a composição química e nutricional 
da "ora-pro-nóbis" para difundir sua utilização à população vegetariana e vegana. Além disso, os objetivos específicos foram o desenvolvimento de uma farinha, para o melhor aproveitamento do teor proteico da planta e melhor comercialização do produto, além da aplicação de um questionário a fim de avaliar o perfil de consumo da Pereskia Aculeata Mill.

\section{MATERIAL E MÉTODOS}

\subsection{Material}

As folhas de ora-pro-nóbis foram coletadas na cidade de Campo Largo, região metropolitana de Curitiba, nas coordenadas 25²6’50.5'S e 49²9'09.0"O, no estado do Paraná em agosto de 2019. As mesmas foram lavadas e acondicionadas sob refrigeração em temperatura média de $7^{\circ} \mathrm{C}$ por um período de cinco dias após a coleta para depois iniciar os procedimentos. Após o quarteamento da amostra para homogeneização da mesma, foram realizadas as análises descritas a seguir e a produção de farinha de ora-pro-nóbis.

\subsection{Metodologia}

\subsubsection{Avaliação Macroscópica}

A partir da observação das amostras coletadas, foi verificada a presença das características típicas da espécie vegetal como caules finos sublenhosos, onde há inserção de folhas largas com poucos espinhos e flores solitárias na extremidade (DUARTE; HAYASHI, 2005).

\subsubsection{Obtenção da Farinha}

Para a obtenção da farinha, as folhas de ora-pro-nóbis foram trituradas e colocadas em papel absorvente e mantidas em estufa regulada a $40^{\circ} \mathrm{C}$ até a secagem completa, processo semelhante ao descrito em Arruda et al (2016) e Pires, Santos e Silva (2019).

\subsubsection{Determinação da Porção}

A determinação da porção ocorreu mediante a utilização de um pires como medida 
caseira e pesagem em balança semianalítica em triplicata, sendo obtida posteriormente a média e o desvio padrão da porção definida.

\subsubsection{Determinação da Composição Química e Nutricional}

Para as folhas frescas de Pereskia Aculeata Mill. e para a farinha, foram realizadas as determinações de umidade (voláteis a 105)ㄱำ, lipídeos (extrato etéreo) e resíduo mineral fixo (cinzas), segundo as normas descritas pelo Instituto Adolfo Lutz (IAL) (2008). Para o procedimento de determinação de nitrogênio total seguiu-se o método de Kjeldahl, de acordo com a Association of Official Agricultural Chemists (AOAC) (1995), com posterior cálculo de teor de proteína através do fator de conversão 6,25, segundo Sllveira (2010). Além disso, a determinação de fibras foi obtida através da AOAC (1995) e, por último, foi realizada a diferença para obtenção de carboidratos. Todas as análises foram realizadas em triplicata, exceto a determinação de lipídeos, que foi feita em duplicata.

\subsubsection{Avaliação do Perfil de Consumo de Ora-Pro-Nobis}

Foi aplicado, concomitantemente à pesquisa, um questionário (anexo 1) a fim de avaliar perfil do consumo de ora-pro-nóbis. O mesmo foi aplicado por meio da plataforma Google Formulários, no período do dia 11 de novembro a 14 de novembro, e foi respondido por estudantes do curso de Farmácia da Universidade Federal do Paraná e pela comunidade externa. O questionário não foi submetido para avaliação do Comitê de Ética em Pesquisa pois, conforme a Resolução n 510, de 07 de abril de 2016, do Comitê de Ética em Pesquisa, no artigo 1ํㅡㄹ parágrafo único, pesquisas de opinião com participantes não identificados não necessitam de registro e avaliação pelo sistema CEP/CONEP (MINISTÉRIO DA SAÚDE, 2016).

\section{RESULTADOS E DISCUSSÃO}

\subsection{Avaliação Macroscópica}

A análise da avaliação macroscópica revelou folhas alongadas, arredondadas e lisas, de coloração verde nuances, sendo o verso mais escuro. Além disso, percebeu-se a presença de manchas e furos. Enquanto algumas se apresentavam firmes, outras estavam 
maleáveis.

Tal resultado coincide parcialmente com informações apresentadas em outros trabalhos: as folhas da espécie são verdes e suculentas, com bordas avermelhadas. Apresentam aproximadamente $7 \mathrm{~cm}$ de comprimento, $3 \mathrm{~cm}$ de largura e formato elíptico (SQUENA et al., 2012). São folhas simples, simétricas e apresentam textura coriácea, com cerca de $7 \mathrm{~cm}$ de comprimento e 3cm de largura. (DUARTE; HAYASHI, 2005).

É importante ressaltar que dependendo da intensidade da luz, pode haver uma mudança na estrutura anatômica das folhas (PAULA, 2018).

\subsection{Obtenção de Farinha}

Após 72 horas de secagem em estufa regulada a $40^{\circ} \mathrm{C}$, obteve-se a farinha de orapro-nóbis, apresentando aspecto de coloração verde escuro intenso, odor da planta característico e sabor agradável. Foi, posteriormente, utilizada para avaliação de sua qualidade nutricional. A farinha foi acondicionada em frascos de vidro fechados durante todo o processo de análise, mantendo-se nas mesmas condições durante 6 meses.

\subsection{Determinação da Porção}

A análise da porção é importante pois define a quantidade de consumo por refeição de um alimento. Através de pesquisas na literatura, foi determinado que a porção de orapro-nóbis é de um pires de folhas. Os resultados obtidos forneceram que cada pires de folha corresponde a um valor médio de 52,20 g $( \pm 7,05)$.

\subsection{Composição Centesimal}

Após as análises da composição química e nutricional realizadas com as folhas de ora-pro-nóbis, os resultados da composição química e nutricional obtidos em $100 \mathrm{~g}$ de amostra úmida e seca foram reunidos e estão descritos na tabela 1. 
Tabela 1: Resultados da composição química e nutricional de Pereskia aculeata Mill. (orapro-nobis) em $100 \mathrm{~g}$ de produto,em base úmida (folhas frescas) e em base seca (farinha).

\begin{tabular}{lcc}
\hline \multicolumn{1}{c}{ DETERMINAÇÃO } & $\%$ BASE ÚMIDA & $\%$ BASE SECA \\
\hline Umidade & $84,79 \%( \pm 0,28)$ & $7,15 \%( \pm 0,24)$ \\
Proteína* $^{*}$ & $2,37 \%( \pm 0,09)$ & $15,61 \%( \pm 0,57)$ \\
Lipídeos & $0,44 \%( \pm 0,02)$ & $2,88 \%( \pm 0,11)$ \\
Carboidratos ${ }^{* *}$ & - & - \\
Fibras & $10,05 \%( \pm 1,48)$ & $66,06 \%( \pm 9,75)$ \\
Minerais & $2,68 \%( \pm 0,14)$ & $17,61 \%( \pm 0,97)$ \\
Kcal & $13,44 \mathrm{Kcal}( \pm 0,02)$ & $88,36 \mathrm{Kcal}( \pm 0,72)$ \\
\hline
\end{tabular}

* Fator de conversão: 6,25 (SILVEIRA, 2010).

${ }^{* *}$ Calculado por diferença.

Os valores da porcentagem de fibras totais em $100 \mathrm{~g}$ de amostra seca e úmida encontrados na literatura apresentaram divergências com os valores determinados no presente estudo, apesar de terem sido utilizados os mesmos métodos para a determinação (AOAC, 1995). Em amostra úmida, o valor experimental se aproxima do dobro do valor teórico, enquanto em amostra seca apresentou valor cerca de $26 \%$ maior do que os encontrados no estudo de Martinevski et al. (2013).

É importante se observar também os valores dos desvios padrão obtidos no cálculo da porcentagem de fibras totais. No trabalho de Martinevski et al. (2013), os valores calculados foram 0,07 para matéria úmida e 0,54 para matéria seca, valores significativamente menores dos encontrados no presente estudo, 1,45 e 9,75 para amostras úmida e seca, respectivamente. Um desvio padrão grande significa que os valores amostrais estão bem distribuídos em torno da média, indicando que as amostras de análise neste estudo não eram homogêneas, o que pode ter interferido nos resultados da análise.

Nos resultados obtidos da porcentagem de carboidratos, as diferenças em relação aos valores encontrados na literatura também foram relevantes. Enquanto não foram encontrados valores experimentais significativos de carboidratos tanto em amostra úmida quanto seca, foi relatado no estudo de Martinevski et al. (2013) uma porcentagem de 3,29\% em amostra úmida e 24,80\% em amostra seca. Em ambos os estudos, os valores para carboidratos foram determinados por diferença, segundo a equação: 


\section{Carboidratos totais $(\%)=[100$ - (umidade + lipídeos + proteína + cinzas $)]$}

Além disso, existe uma diferença no valor de proteínas obtido nesse estudo e nos estudos encontrados na literatura. Neste trabalho chegou-se a $15,61 \%$ em base seca, abaixo do que Takeiti et al. (2008) obteve, por exemplo, que foi o valor de $28,4 \%( \pm 0,4)$ em base seca. $O$ método utilizado em ambos os estudos foi o mesmo, a determinação pelo método de Kjeldahl de acordo com a AOAC (1995), com posterior cálculo de teor de proteína através do fator de conversão 6,25 segundo Silveira (2010).

De acordo com Figueiredo (2010, apud VARGAS, 2019), vários fatores interferem na produção de metabólitos nas espécies, entre esses, atualmente sabe-se que a sazonalidade exerce destacada importância. No presente estudo e no de Martinevski et al. (2013), a coleta foi feita em estados da região sul do Brasil, porém em diferentes épocas do ano, enquanto no trabalho realizado por Takeiti et al. (2008), a coleta foi feita no estado de São Paulo, no sudeste brasileiro. Isso pode ter interferido na composição química da planta, provocando variações nos resultados encontrados nas análises. Neste estudo, coletou-se a amostra no mês de agosto, período de inverno, no qual havia pouca incidência de luz solar e temperatura ambiente baixa, diferentemente do estudo feito por Martinevski et al. (2013), no qual a coleta foi realizada nos meses de maio e junho, ou seja, no outono. Outros fatores que podem ter sido determinantes foram as condições nas quais a planta foi mantida após a coleta. No presente trabalho, a planta foi refrigerada após a lavagem em uma temperatura média de $7^{\circ} \mathrm{C}$ por 5 dias após a coleta, o que não foi relatado no trabalho de Martinevski et al. (2013).

Os valores determinados de umidade, lipídeos (extrato etéreo) e minerais estão de acordo aqueles encontrados na literatura. No presente estudo, foram utilizadas as metodologias descritas pelo IAL (2008) para esses três componentes.

\subsection{Informação Nutricional}

A partir das medidas caseiras de um pires para as folhas frescas e de uma colher de sopa de matéria seca, 52,20 g e 6,00 g respectivamente, foi obtida a informação nutricional, de acordo com a RDC 360 (BRASIL, 2003). Os resultados obtidos então descritos nas tabelas 2 e 3 . 
Tabela 2: Informação nutricional* de Pereskia aculeata Mill. (ora-pro-nobis) nas porções em medida caseira úmida (fresca): um pirex- 52,00 g.

\begin{tabular}{lcc}
\hline INFORMAÇÃO & MASSA NA PORÇÃO & VD\% \\
\hline Valor energético & $7,03 \mathrm{kCal}$ & $0,35 \%$ \\
Carboidratos & - & - \\
Proteínas & $1,24 \mathrm{~g}$ & $6,61 \%$ \\
Gorduras totais & $0,23 \mathrm{~g}$ & $3,76 \%$ \\
Fibras & $5,25 \mathrm{~g}$ & $21,0 \%$ \\
\hline
\end{tabular}

Tabela 3: Informação nutricional* de Pereskia aculeata Mill. (ora-pro-nobis) nas porções em medida caseira seca (farinha): uma colher de sopa - 6,0 g

\begin{tabular}{lcc}
\hline INFORMAÇÃO & MASSA NA PORÇÃO & VD\% \\
\hline Valor energético & $5,49 \mathrm{kCal}$ & $0,27 \%$ \\
Carboidratos & - & - \\
Proteínas & $0,94 \mathrm{~g}$ & $5,01 \%$ \\
Gorduras totais & $0,17 \mathrm{~g}$ & $2,78 \%$ \\
Fibras & $3,96 \mathrm{~g}$ & $15,84 \%$ \\
\hline
\end{tabular}

* A partir da RDC 360 (BRASIL, 2003).

A ora-pro-nóbis apresentou valores de 1,24 g de proteína em um pires de produto fresco (aproximadamente 52,20 g) e de 0,94 g de proteína em 6,0 g de matéria seca, equivalentes a uma colher de sopa. De acordo com a RDC 360 (BRASIL, 2003), em uma dieta de 2000 Kcal devem ser consumidos 75 g de proteína. Para que esse valor seja atingido, deveriam ser consumidos $3.157,26 \mathrm{~g}$ ora-pro-nóbis fresca, em torno de 60 pires, e 479,17 g de matéria seca, aproximadamente 83 colheres de sopa. 
De acordo com a Portaria oㅡ 27/98 do Ministério da Saúde, um alimento pode ser considerado fonte de proteínas quando possuir no mínimo $10 \%$ da ingestão diária recomendada em $100 \mathrm{~g}$ de alimento, e é considerado rico em proteínas quando apresenta no mínimo de $20 \%$ da ingestão diária recomendada em $100 \mathrm{~g}$.

Dessa forma, a utilização da Pereskia aculeata Mill como fonte proteica é inviável, contestando o conhecimento popular. Mesmo a sua forma seca, na qual a cactácea apresentou um teor proteico mais elevado, não pode ser utilizada como única fonte de proteínas.

Tanto a farinha quanto as folhas de ora-pro-nóbis podem ser utilizadas para a variação da alimentação. No caso da farinha, pode ainda ser utilizada como uma suplementação, mas não deve substituir a ingestão de alguma leguminosa, como o feijão e a soja, por exemplo.

\subsection{Pesquisa de Opinião}

Para avaliar o perfil de consumo da planta foi feita uma pesquisa de opinião, da qual participaram sessenta pessoas, com idade acima de 13 anos e abaixo de 60 , sendo que $13,3 \%$ tinham entre 13 e 18 anos, $81,7 \%$ tinham entre 19 e 40 anos e os outros $5 \%$ tinham acima de 40 anos. Do total de participantes, $26,7 \%$ relataram ser veganos ou vegetarianos e $48,3 \%$ conheciam a planta ora-pro-nóbis. Esse conhecimento se deu em $51,7 \%$ por indicação de parentes ou amigos, $20,7 \%$ por pesquisa própria e $27,6 \%$ por outros motivos.

Dos participantes da pesquisa, apenas $44,8 \%$ já consumiu a planta, sendo esse consumo $23,1 \%$ in natura, $53,8 \%$ refogada, $30,8 \%$ na sopa e também $30,8 \%$ na salada. Entretanto, nenhum deles relatou consumo em forma de suco, cápsula ou farinha. Desta forma, essa resposta foi ao encontro de um dos objetivos do trabalho, que é a elaboração de farinha para o enriquecer alimentos, o que, de acordo com a pesquisa, não é habitual.

Dentre os motivos citados para o consumo, a maioria justificou o uso pela quantidade de proteínas contida na planta, bem como pela quantia de fibras e nutrientes.

\section{CONCLUSÃO}

As folhas de Ora-pro-nóbis analisadas neste estudo mostraram, apesar de algumas divergências, valores de fibras e proteínas consistentes com demais pesquisas já 
realizadas, confirmando satisfatoriamente o seu potencial de ser utilizada por pessoas que apresentam necessidade de consumir fontes alternativas de proteínas. Contudo deve ser ressaltado que, para cumprir este papel de fonte alternativa de proteínas, a ora-pro-nóbis é muito mais vantajosa se consumida em forma seca, visto que, comparado a outros vegetais mais conhecidos, como o grão de bico (que apresenta aproximadamente 8,9g de proteína em $100 \mathrm{~g}$ de alimento) e o feijão (aproximadamente $5 \mathrm{~g}$ de proteína em $100 \mathrm{~g}$ de alimento), as folhas de ora-pro-nóbis apresentam apenas $2,37 \mathrm{~g}$ de proteína em $100 \mathrm{~g}$. Porém, este número salta consideravelmente quando analisada em base seca, passando a apresentar 15,65g de proteína em 100g. De acordo com a RDC 360 (BRASIL, 2003), uma dieta de 2000 Kcal deve incluir $75 \mathrm{~g}$ de proteína. Analisando, contudo, as respostas do questionário, a farinha não se caracteriza como a forma mais consumida de ora-pro-nóbis, o que reflete em um possível desconhecimento da população sobre este fato, o que pode provocar um risco de carência proteica em quem a consome in natura e não tem conhecimento da real quantidade de proteínas presente na planta, uma vez que a suplementação proteica é um dos principais objetivos das pessoas que a utilizam. As plantas alimentícias não convencionais (PANCs), como a ora-pro-nóbis, são uma ótima opção de alimentos para pessoas de baixa renda e para aquelas que estão atentas às causas de sustentabilidade, visto que são facilmente cultivadas em casa, muitas vezes são endêmicas, e possuem grande potencial benéfico para o ser humano. Acredita-se que o consumo de PANCs deve ser incentivado, mas com a condição de que as informações sejam corretamente repassadas à população, como no caso acima apresentado. Também deve-se levar em consideração de que, por serem cultivadas sem métodos e critérios rígidos, seus conteúdos nutricionais são difíceis de serem padronizados. Como último adendo, sugere-se que mais análises nutricionais da ora-pro-nóbis sejam realizadas, levantando questões como fatores anti-nutricionais, por exemplo, o que contribuiria para um melhor estabelecimento de seu perfil nutricional.

\section{REFERÊNCIAS}

AGOSTINI-COSTA, T. S.; WONDRACECK, D. C.; ROCHA, W. S.; SILVA, D. B. Carotenoids profile and total polyphenols in fruits of Pereskia aculeata Miller. Revista Brasileira de Fruticultura, v. 34, n. 1, p. 234-238, 2012. 
ALMEIDA FILHO, J.; CAMBRAIA, J. Estudo do valor nutritivo do "ora-pro-nobis" (Pereskia aculeata Mill.). Revista Ceres, v. 21, n. 114, p. 105-111, 1974.

ALMEIDA; M. E. F.; JUNQUEIRA, A. M. B.; SIMÃO, A. A.; CORRÊA, A. D. Caracterização química das hortaliças não-convencionais conhecidas como ora-pro-nobis. Bioscience Journal, v. 30, n. 1, p. 431-439, 2014.

ASSOCIATION OF OFFICIAL AGRICULTURAL CHEMISTS. Official Methods of Analysis. USA: ASSOCIATION OF OFFICIAL AGRICULTURAL CHEMISTS, Washington D.C. 1995

BATISTA, L. M. L.; SILVA, W. J. M.; ALMEIDA, M. A. B.; RODRIGUES, A. C. P.; ALVES, T. N. P. Perfil Nutricional de Crianças Assistidas pela Pastoral do Bairro 223 Borboleta, Juiz de Fora, MG. In: CONGRESSO BRASILEIRO DE EXTENSÃO UNIVERSITÁRIA, 2, 2004. Belo Horizonte. Anais... Belo Horizonte: UFMG, 2004.

BRASIL. Ministério da Agricultura, Pecuária e Abastecimento. Secretaria de Desenvolvimento Agropecuário e Cooperativismo. Manual de hortaliças não convencionais. Brasília, 2010. 92 p.

BRASIL. Ministério da Saúde. Agência Nacional de Vigilância Sanitária (ANVISA). RDC № 360, DE 23 DE DEZEMBRO DE 2003. Regulamento Técnico sobre Rotulagem Nutricional de Alimentos Embalados, tornando obrigatória a rotulagem nutricional. Diário Oficial da República Federativa do Brasil, Brasília, 23 dez. 2003.

DUARTE, M. R.; HAYASHI, S. S. Estudo anatômico de folha e caule de Pereskia aculeata Mill. (Cactaceae). Revista Brasileira de Farmacognosia, v. 15, n. 2, p. 103-109, 2005.

IAL. Instituto Adolfo Lutz. Normas analíticas do Instituto Adolfo Lutz: métodos químicos e físicos para análise de alimentos. São Paulo: Instituto Adolfo Lutz, 2008. 1020 p.

KINUPP, V.F.; BARROS, I.B.I. Teores de proteína e minerais de espécies nativas, potenciais hortaliças e frutas. Food Science Technology, v. 28, n. 4, p. 846-857, 2008. 
LOPES, W. A. L.; SOUZA, L. A.; MOSChETA, I. M.; ALBIERO, A. L. M.; MOURÃO, K. S. M. A comparative anatomical study of the stems of climbing plants from the forest remnants of Maringá, Brazil. Gayana Botanica, v. 65, n. 1, p. 28-38, 2008.

MAZIA, R. S. Influência do tipo de solo usado para o cultivo de Pereskia aculeata sobre propriedade proteica. Revista Saúde e Pesquisa, v. 5, n. 1, p. 59-65, 2012.

MARTINEVSKI, C. S. et al. Utilization of Bertalha (Anredera cordifolia (Ten.) Steenis) and ora pro nobis (Pereskia aculeata Mill.) in preparing breads. Braz. J. Food Nutr, v. 24, p. $272,2013$.

PATERSON, I. D.; DOWNIE, D. A.; HILL, M. P. Using molecular methods to determine the origin of weed populations or Pereskia aculeate in South Africa and its relevance to biological control. Biological Control, v. 48, n. 1, p. 84-91, 2009.

ROCHA, S. A.; LIMA, G. P. P.; LOPES, A. M.; BORGUINI, M. G.; CICCONE, V. R.; BELUTA, I. Fibras e lipídios em alimentos vegetais oriundos do cultivo orgânico e convencional. Revista Simbio-Logias, v. 1, n. 2, p. 1-9, 2008.

ROSA, S. M.; SOUZA, L. A. Morfo-anatomia do fruto (hipanto, pericarpo e semente) em desenvolvimento de Pereskia aculeata Miller (Cactaceae). Biological Sciences, v. 25, n. 2, p. 415-428, 2003.

SCHEINVAR, L. Flora llustrada Catarinense: Cactaceas. Itajaí: Herbário Barbosa Rodrigues, 1995. v. 1, 377 p.

SILVA JÚNIOR, A. A.; NUNES, D. G.; BERTOLDI, F. C.; PALHANO, M. N.; KOMIEKIEWICZ, N. L. K. Pão de ora-pro-nobis - um novo conceito de alimentação funcional. Agropecuária Catarinense, v. 23, n. 1, p. 35-37, 2010.

SILVEIRA, M. G. Ensaio nutricional de Pereskia spp.: Hortaliça não convencional. 174 f. Tese (Doutorado em Ciência dos Alimentos), Universidade Federal de Lavras, Lavras, 2016. 
SOUZA, C. O.; SILVA, R. C. R.; ASSIS, A. M. O.; FIACCONE, R. L.; PINTO, E. J.; MORAES, L. T. L. P. Associação entre inatividade física e excesso de peso em adolescentes de Salvador, Bahia, Brasil. Revista Brasileira de Epidemiologia, v. 13, n. 3, p. 468-475, 2010.

SOUZA, M. R. M.; CORREA, E. J. A.; GUIMARÃES, G.; PEREIRA, P. R. G. O potencial do ora-pro-nobis na diversificação da produção agrícola familiar. Revista Brasileira de Agroecologia, v. 4, n. 2, p. 3550-3554, 2009.

TAKEITI, C. Y.; ANTONIO, G. C.; MOTTA, E. M. P.; COLLRES-QUEIROA, F. P.; PARK, K. J. Nutritive vegetable (Pereskia aculeata Mill). Internacional Journal of Food Sciences and Nutrition, v. 60, n. 1, p. 1-13, 2009.

The Plant List. Disponível em: <http://www.theplantlist.org/tpl1.1/record/kew-2414656>. Acesso em 4 ago. 2019

Tropicos. Missouri, 2019. Disponível em: <http://www.tropicos.org/NameSearch.aspx?name= Pereskia+aculeata>. Acesso em: 4 nov. 2019

TOFFANELI, M. B. D.; RESENDE, S. G. Sistemas de condução na produção de folhas de Ora-pro-nobis. Pesquisa Agropecuária Tropical, v. 41, n. 3, p. 466-469, 2011.

VARGAS, A. G. de., ROCHA, R. D. C. da., TEIXEIRA, S. D. Influência da sazonalidade na composição centesimal da Pereskia aculeata Miller. Synergismus scyentifica UTFPR, Pato Branco, v. 12, n. 1, p. 1-7. 2017. Disponível em <https: //periodicos.utfpr.edu.br/synscy>. Acesso em: 5 nov. 2019.

\footnotetext{
*Autor para correspondência:

Maria Eugênia Balbi

Professora do Curso de farmácia da Universidade Federal do Paraná

Rua Pref. Lothário Meissner, 632, Jardim Botânico,

CEP 80210-170 - Curitiba - PR

Recebido: 22/08/2020 Aceite: 29/09/2020
} 